\title{
Double aortic arch and complex cardiac malformations
}

\author{
R. E. Hawker ${ }^{1}$, J. M. Celermajer, T. B. Cartmill, and J. D. Bowdler \\ From the Adolph Basser Institute of Cardiology, Royal Alexandra Hospital for Children, \\ Sydney, Australia
}

$A$ case of double aortic arch and D-transposition of the great arteries is described. It is thought that this combination of lesions has not previously been reported. Attention is drawn to the problems encountered in management of this potentially reparable situation.

Vascular ring caused by double aortic arch most commonly occurs as an isolated anomaly (Keith, Rowe, and Vlad, 1967). However, its association with pulmonary stenosis (Bahnson and Blalock, 1950), tetralogy of Fallot (Griswold and Young, 1949; Stewart, Kincaid, and Edwards, 1964), truncus arteriosus (Kerwin, 1936), ventricular septal defect and left superior vena cava (Lincoln et al., 1969), and coarctation (Stewart et al., 1964), has been described. This paper reports the association of double aortic arch and D-transposition of the great arteries, ventricular septal defect, and pulmonary stenosis, and is thought to be the first such case report.

\section{Case report}

A $4000 \mathrm{~g}$ male infant was transferred to the Royal Alexandra Hospital for Children at I3 days of age. He had been mildly cyanosed since birth, with episodes of more severe cyanosis, stridor, and intercostal recession. His pulses were normal and there was a prominent right ventricular heave, a grade $2 / 4$ ejection murmur maximal at the left sternal edge, and a single second heart sound. Loud inspiratory and expiratory noises were heard over both lung fields. There was no heart failure. The electrocardiogram was normal. Chest $x$-ray (Fig. I) showed a normal sized heart, right-sided aortic arch, and diminished pulmonary vascularity. Conspicuous narrowing of the trachea approximately $\mathrm{I} \mathrm{cm}$ above the carina was noted. $X$-rays of the barium-filled oesophagus (Fig. 2) showed a persistent filling defect posteriorly and on the left lateral aspect, and a diagnosis of vascular ring with cyanotic congenital heart disease was made. Cardiac catheterization and angiocardiography established a diagnosis of

\footnotetext{
${ }^{1}$ Present address: Department of Cardiology, The Hospital for Sick Children, 555 University Avenue, Toronto 2, Ontario, Canada.
}

D-transposition of the great arteries with double aortic arch, ventricular septal defect, and pulmonary stenosis (Fig. 3). The right and left aortic arches were interpreted as being about equal in size.

Via a right posterolateral thoracotomy, the right arch was divided beyond the right subclavian artery and dissected anteriorly until the trachea and oesophagus were free. The postoperative course was complicated by respiratory obstruction due to tracheomalacia. The affected segment was only 0.25 to $0.5 \mathrm{~cm}$ above the carina so that the endotracheal tubes if advanced too far repeatedly caused collapse of the left lung or the upper lobe of the right lung. However, at times when his lungs were well inflated he was only mildly cyanosed, indicating that the cardiac lesion

FIG. I Chest $\mathrm{x}$-ray. Heart slightly enlarged. Absence of main pulmonary artery segment. Peripheral pulmonary vascularity is within normal limits.

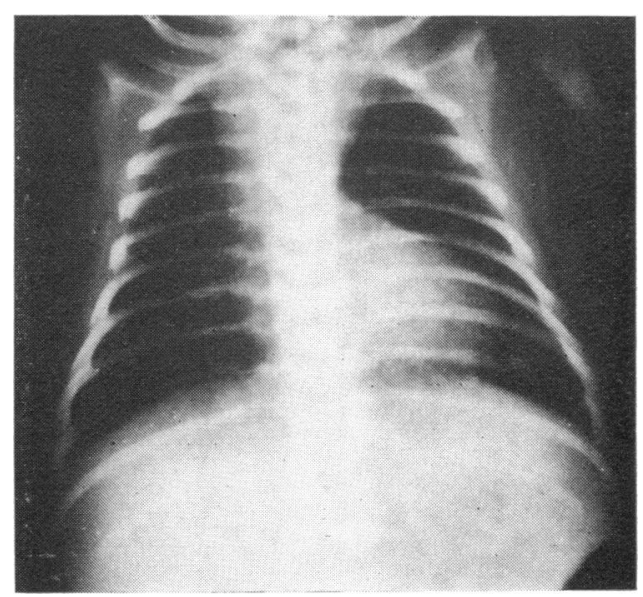


was well compensated. Tracheostomy was performed after 13 days. The wound became infected with Pseudomonas pyocyaneus, with subsequent respiratory infection which led to his death 30 days after operation.

Necropsy confirmed the diagnosis of transposition of the great arteries, pulmonary stenosis, and large ventricular septal defect. The obstruction to the trachea and the oesophagus was probably adequately relieved by the wide division of the right aortic arch. The tracheal cartilage was microscopically normal and the lungs showed lipoid pneumonia.

\section{Discussion}

The presentation, radiological features, and the complications after operation are typical of symptomatic vascular rings in the neonatal period. A radiograph of the barium-filled oesophagus showing compression from both sides, behind and often from in front as well, is said to be characteristic of double aortic arch (Neuhauser, I946). This was not seen in this case probably because of the atypical position of the transposed aorta.

The resultant clinical picture was difficult to interpret since the vascular ring and the transposition of the great arteries were both causes of cyanosis. Despite the complexity of the lesions however, total correction was potentially feasible. Relief of the tracheal obstruction left the baby only mildly cyanosed, and had he survived his respiratory complications, the cardiac malformation might have been corrected by the Rastelli technique (Rastelli, Wallace, and Ongley, 1969).

In retrospect, a left thoracotomy should probably have been performed. In 95 per cent

FIG. 2 Spot film of barium swallow.

Narrowing of tracheal lumen about $0.5 \mathrm{~cm}$ above the carina and narrowing of the oesophagus at the same level.

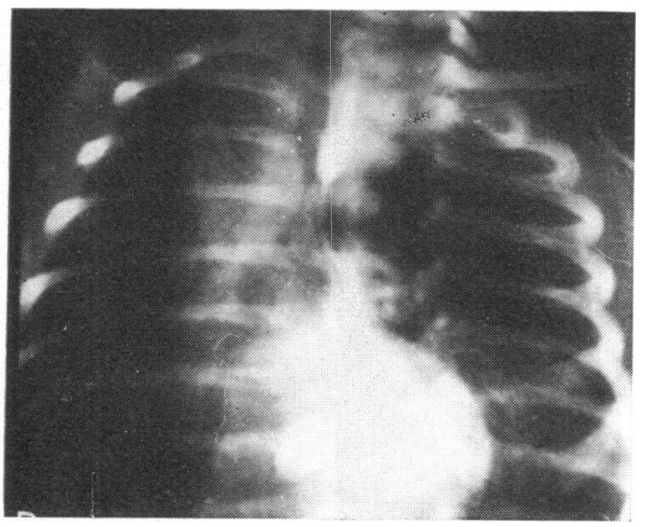

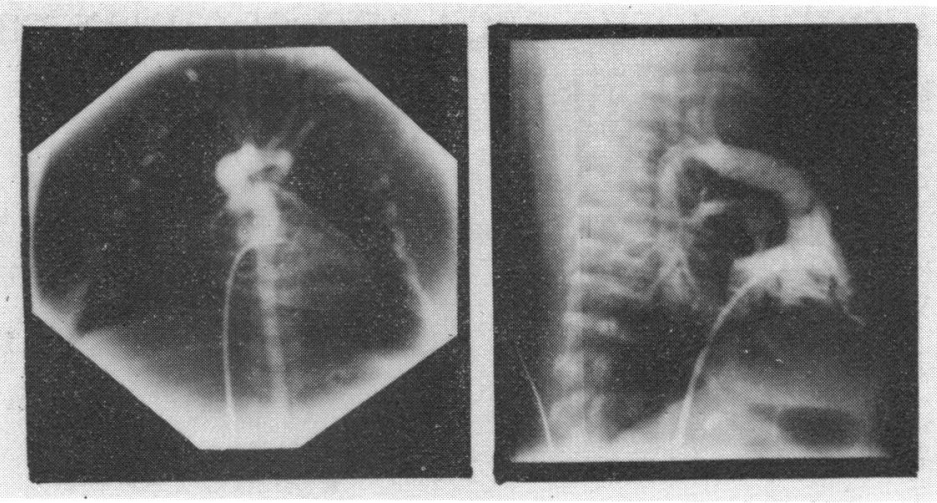

FIG. 3 Angiocardiogram. Transposed aorta arising from anterior ventricle via an infundibulum. Pulmonary artery arising from posterior ventricle with subvalvar stenosis.

Double aortic arch forming a vascular ring.

of cases the left arch is smaller than the right and a left anterolateral approach is preferred by most surgeons (Moss and Adams, 1968). Access in this case seemed easier from the right side, and initially the arches were not thought to be significantly different in size. Relative difficulties might have been encountered had the need for palliative surgery for the cyanotic congenital heart disease arisen, since an aorta to right pulmonary artery anastomosis (Waterston, 1962; Cooley and Hallman, 1966; Somerville et al., 1969; Waldhausen et al., 1968) is probably the palliative operation of choice for potentially correctable cyanotic congenital heart disease with diminished pulmonary blood flow.

\section{References}

Bahnson, H. E., and Blalock, A. (1950). Aortic vascular rings encountered in the surgical treatment of congenital pulmonic stenosis. Annals of Surgery, 131, 356.

Cooley, D. A., and Hallman, G. L. (1966). Intrapericardial aortic-right pulmonary arterial anastomosis. Surgery, Gynaecology and Obstetrics, 122, ro84.

Griswold, H. E., and Young, M. D. (1949). Double aortic arch. Report of two cases and review of the literature. Pediatrics, 4, 75I.

Keith, J. D., Rowe, R. D., and Vlad, P. (1967). Heart Disease in Infancy and Childhood, 2nd ed., p. 432. Macmillan, New York.

Kerwin, A. J. (1936). Persistent (partial) truncus arteriosus associated with double aortic arch. fournal of Technical Methods, 15, 142.

Lincoln, J. C. R., Deverall, P. B., Stark, J., Aberdeen, E., and Waterston, D. J. (1969). Vascular anomalies compressing the oesophagus and trachea. Thorax, 24, 295. 
Moss, A. J., and Adams, F. H. (1968). Heart Disease in Infants, Children, and Adolescents. p. 404. Williams and Wilkins, Baltimore.

Neuhauser, E. B. D. (1946). The roentgen diagnosis of double aortic arch and other anomalies of the great vessels. American fournal of Roentgenology, 56, I.

Rastelli, G. C., Wallace, R. B., and Ongley, P. A (1969). Complete repair of transposition of the great arteries with pulmonary stenosis; a review and report of a case corrected by using a new surgical technique. Circulation, 39, 83.

Somerville, J., Yacoub, M., Ross, D. N., and Ross, K. (1969). Aorta to right pulmonary artery anastomosis (Waterston's operation) for cyanotic heart disease. Circulation, 39, 593.

Stewart, J. R., Kincaid, O. W., and Edwards, J. E. (1964). An Atlas of Vascular Rings and Related Malformations of the Aortic Arch System, p. I9. Charles C. Thomas, Springfield, Illinois.
Waldhausen, J. A., Friedman, S., Tyers, G. F. O., Rashkind, W. J., Petry, E., and Miller, W. W. (1968). Ascending aorta - right pulmonary artery anostomosis. Clinical experience with 35 patients with cyanotic congenital heart disease. Circulation, 38, 463.

Waterston, D. J. (1962). Treatment of Fallot's tetralogy in infants under the age of one year. Rozhledy $v$ chirurgii, 41, 181.

Requests for reprints to Dr. J. M. Celermajer, Adolph Basser Institute of Cardiology, Royal Alexandra Hospital for Children, Pyrmont Bridge Road, Camperdown 2050, New South Wales, Australia. 